Article

\title{
Experimenting with Odour Proficiency Tests Implementation Using Synthetic Bench Loops
}

\author{
Domenico Cipriano $^{1, *(\mathbb{D})}$, Amedeo M. Cefalì ${ }^{1,2}$ and Marco Allegrini $^{3}$ \\ 1 RSE-Ricerca sul Sistema Energetico, Via Rubattino 54, 20131 Milan, Italy; amedeomanuel.cefali@rse-web.it \\ 2 Department of Earth and Environmental Sciences, University of Milano-Bicocca, Piazza della Scienza 1, \\ 20126 Milan, Italy \\ 3 Politecnico di Milano, Piazza Leonardo da Vinci 32, 20133 Milan, Italy; marco.allegrini1993@libero.it \\ * Correspondence: domenico.cipriano@rse-web.it; Tel.: +39-329-6873394
}

check for updates

Citation: Cipriano, D.; Cefalì, A.M.; Allegrini, M. Experimenting with Odour Proficiency Tests

Implementation Using Synthetic Bench Loops. Atmosphere 2021, 12, 761. https://doi.org/10.3390/ atmos12060761

Academic Editors: Günther Schauberger, Martin Piringer, Chuandong Wu and Jacek Koziel

Received: 21 April 2021

Accepted: 8 June 2021

Published: 12 June 2021

Publisher's Note: MDPI stays neutral with regard to jurisdictional claims in published maps and institutional affiliations.

Copyright: (c) 2021 by the authors. Licensee MDPI, Basel, Switzerland. This article is an open access article distributed under the terms and conditions of the Creative Commons Attribution (CC BY) license (https:/ / creativecommons.org/licenses/by/ $4.0 /)$.

\begin{abstract}
Uncertainty in the quantification of odour measurements is a difficult (but needed) task Critical aspects include panel selection (required by dynamic olfactometry), sampling, and stability of the samples. Proficiency tests (PTs) can help evaluate such contributions; however, the classical approach to PTs, in which laboratories analyse real samples taken from the field, are not as applicable in this field, and are often implemented by only using dry gas cylinders containing stable compounds. Consequently, uncertainties related to the sampling activity cannot be assessed. In particular, high odour levels and the presence of water vapour in emission sources can create significative biases due to sampling techniques used and chemical reactions that can occur before analysis. In this work, we present experimental notes, developed using the experimental facility 'LOOP', realised at the RSE research centre in Italy, in order to "help" the definition, in an upgraded protocol for implementing PTs for odour determinations. Using this bench loop is advantageous as it involves the possibility of implementing samples in conditions very similar to reality (i.e., high temperatures, high water content, and the presence of chemical interferents).
\end{abstract}

Keywords: olfactometry; proficiency test; bench loop; n-butanol; sampling uncertainties

\section{Introduction}

In Europe, odour concentration is determined by means of dynamic olfactometry, as standardised in EN 13,725 [1]. As 'odour' is defined as the effect of a gas sample to the human nose, with no relation to the chemical composition of the sample itself, the determination of uncertainty is very delicate and complicated. One major source is related to the human panel, where components are selected on an empirical basis.

Other factors affecting measurement uncertainty are sample collections, transport, and storage $[2,3]$.

Proficiency tests (PTs) are fundamental tools to improve knowledge on odour measurements; generally, PT schemes are based on analyses by participating laboratories of reference materials [4,5], for example, environmental samples [6,7] delivered by proficiency test providers (PTP). In many cases, sampling is not part of the process, so sampling uncertainties cannot be assessed, but are often considered negligible, and are included in the preparation process of the references.

In this particular application, the effects, due to sampling and stability of the sample, cannot be neglected, particularly because of the possible presence of high humidity levels that require specific sampling procedures (i.e., using dilution probes), which could alter the sample characteristics significantly. Moreover, the presence of chemical compounds, even if they are not directly considered 'odorants' (i.e., carbon dioxide), can chemically alter the sample and its effect on the panellist and, thus, should be investigated.

The aim of the present work if to provide a first evaluation to extend proficiency testing schemes to odour measurements. 
In past years, PT exercises on odours were conducted by the Hessian Agency for Nature Conservation, the Environment and Geology (HLUG) in Kassel, Germany [8]. Due to specific design of the experimental device, levels of humidity and composition of the matrix gas (air, in that case) could not be widely modified to reach real concentrations present in stack emissions.

For this scope, in 2012 a full-synthetic bench loop was realised by RSE in Milan; it was based on controlled flow injections of known gases in a closed bench loop, allowing definition of the effluent gases and of the related reference values on a metrological basis [9].

\section{Materials and Methods}

\subsection{General}

The data presented in this publication were obtained during preliminary experimental work, using RSE's bench loop (Figure 1), used to generate an odorous sample with a known odour concentration. N-butanol, indicated as reference material in the standard EN 13,725, was used as the first component investigated.
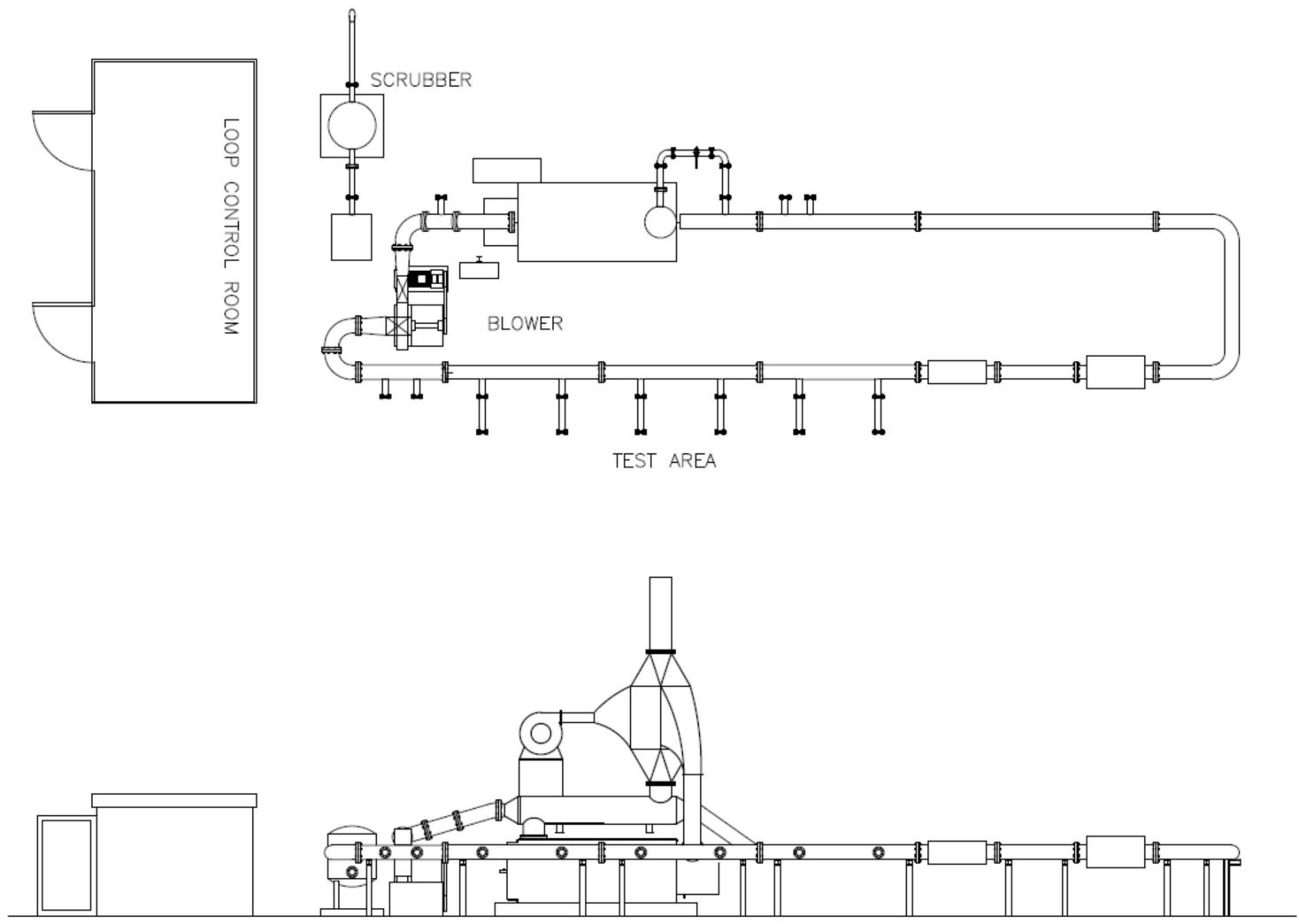

Figure 1. Mechanical dimensions of the LOOP facility.

This first experiment was conducted in order to verify the possibility of implementing odour PTs using RSE's loop test bench.

Using this bench is advantageous-it means the possibility of generating more 'realistic' mixtures, with high values of humidity (up to $10 \% v / v$ ), temperatures (between $60^{\circ} \mathrm{C}$ and $\left.180^{\circ} \mathrm{C}\right)$, and gas matrix composition $\left(\mathrm{CO}_{2}, \mathrm{O}_{2}\right.$, and other compounds) where, even if they are not considered 'odorants', they could alter human perceptions and be considered 'interferents'.

The aim of the first experiment was to verify the possibility of creating a synthetic atmosphere containing n-butanol, $\mathrm{N}_{2}$, and water vapour. As gas cylinders with the desired n-butanol concentrations were not available, it was decided to inject a liquid solution of water and n-butanol into the bench loop using a vaporisation system designed for such a scope. 
Samples taken from the bench loop were analysed by using a GC-FID (DANI Master GC Fast Gas Chromatograph System, DANI Instruments SpA, Milano, Italy) equipped with a capillary column $(20 \mathrm{~m} \times 0.18 \mathrm{~mm} \times 1 \mu \mathrm{m})$. Helium carrier gas was maintained at a constant flow of $0.8 \mathrm{~mL} / \mathrm{min}$.

Moreover, olfactometry determinations were conducted using an olfactometer (T08, ECOMA GmbH, Kiel, Germany) using the same samples.

\subsection{The Bench Loop}

The basic principle of a PT is to feed the measuring system, under test, with a reference material, i.e., a reference gas mixture, and check the abilities of the participating laboratories to analyse the sample and provide consistent results. The challenge in emission monitoring is obtaining a reference material that follows the common definitions normally provided by ISO Guide 35 [10] — as the real matrix is chemically very complex and physically unstablewhile fulfilling the requirements of ISO/IEC 17043 [11]. The experimental facility 'LOOP' is sketched in Figure 1.

Some of its characteristics are:

- Total length of the wind gallery tunnel: about $40 \mathrm{~m}$.

- Internal diameter of the tunnel: $273 \mathrm{~mm}$.

- Internal material: AISI 316.

The LOOP facility is able to generate and maintain, with 'traceable' accuracy and precision reference, atmospheres containing main macro pollutants of interest, with different oxygen and water vapour levels. Full size sampling ports are available to allow participants to use real sampling systems. To obtain the required gaseous mix in the tunnel, a dedicated gas mixing station was realised, making wide use of thermal mass flow controllers using gas cylinders (or from evaporation of liquid reference materials).

Concentrations of various effluents are controlled by means of extractive analysers, which are periodically calibrated; the expanded uncertainty (at a 95\% level) on the various measurements of the measured are from 2 to $5 \%$, respectively.

Together with continuous analysis of gaseous compounds, gas velocity inside the LOOP is monitored using a Pitot tube, connected to absolute and differential pressure gauges, and two 4-wire Pt100 sensors.

The facility has DN 100 standard sampling ports that allows up to five measuring teams to work simultaneously, with a total flow extraction up to $50 \mathrm{~L} / \mathrm{min}$. Pressure inside the test loop is kept over the ambient value.

\subsection{The Vaporisation System}

The solution of $\mathrm{n}$-butanol in water is injected into the LOOP system using a vaporisation system, shown in Figure 2.

The liquid solution rate is regulated and continuously maintained using a calibrated peristaltic pump. Subsequently, it is injected into a heat exchanger that is able to reach temperatures from $130{ }^{\circ} \mathrm{C}$ to $400^{\circ} \mathrm{C}$.

The vapours generated are fluxed inside the LOOP using a heated transfer line.

Then, the vapours are injected into the facility of the area, following the passage of gases in the heater.

The vaporisation system was designed and realised in 2019. It can reach a maximum vaporisation flow rate of $10 \mathrm{~mL} / \mathrm{min}$. 


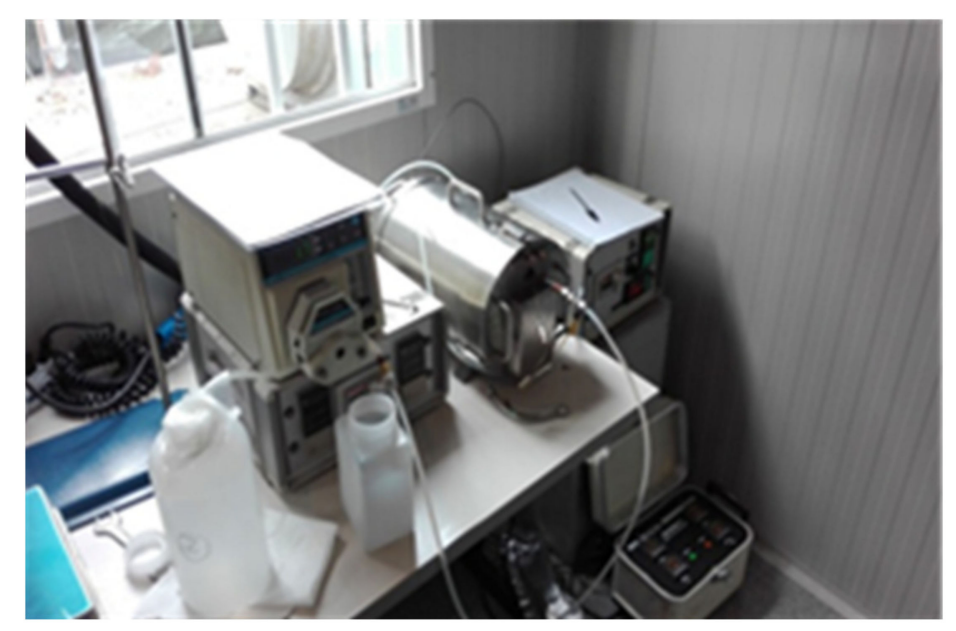

Figure 2. The butanol vaporisation system.

\subsection{Reference Value}

The reference value for $n$-butanol was calculated on the base of total input flow rate, using the following equation:

$$
C_{b u \mathrm{OH}}\left[\mathrm{ppm}_{\mathrm{mol}}\right]=\frac{F_{b u \mathrm{OH}}[\mathrm{mol} / \mathrm{min}]}{F_{\text {gastot }}[\mathrm{mol} / \mathrm{min}]} 10^{6}
$$

where $C_{b u O H}$ is the reference value of $\mathrm{n}$-butanol concentration, expressed in $p p m_{m o l} ; F_{b u O H}$ is the n-butanol flow rate, expressed in $\mathrm{mol} / \mathrm{min} ; F_{\text {gastot }}$ is the total input flow rate, expressed in $\mathrm{mol} / \mathrm{min}$.

In order to calculate the odour concentration, the following equation can be used:

$$
C_{o d}\left[o u E / m^{3}\right]=\frac{C_{b u O H}\left[p p m_{m o l}\right]}{0.04}
$$

where $C_{o d}$ is the reference value of the odour concentration, expressed in $o u E / m^{3}$. This can be assumed as indicated in the standard EN 13725, which establishes that $0.04 \mathrm{ppm}_{\mathrm{mol}}$ of n-butanol is equivalent to $1 \mathrm{ouE} / \mathrm{m}^{3}$.

\subsection{Vaporisation Temperature}

First, the right temperature for the vaporisation of the solution was evaluated. Two different temperatures were selected based on the known characteristics of n-butanol and on experiences with other compounds: $270{ }^{\circ} \mathrm{C}$ and $140{ }^{\circ} \mathrm{C}$.

In Table 1, the expected values of $n$-butanol concentration for the samples generated in each case and the measured values are shown. The measured values were obtained by chemical analysis, carried out with GC-FID gas chromatograph. 
Table 1. Vaporisation temperature tests results.

\begin{tabular}{cccc}
\hline Sample & Tvap $\left({ }^{\circ} \mathbf{C}\right)$ & $\begin{array}{c}\text { CbuOH Expected } \\
(\mathbf{p p m})\end{array}$ & $\begin{array}{c}\text { CbuOH Measured } \\
(\mathbf{1})\end{array}$ \\
\hline 1 & 270 & 23.04 & 14.30 \\
2 & 270 & 38.17 & 5.69 \\
3 & 270 & 76.03 & 15.22 \\
4 & 270 & 76.03 & 30.33 \\
5 & 270 & 78.35 & 37.01 \\
6 & 270 & 154.29 & 55.61 \\
7 & 140 & 24.62 & 18.02 \\
8 & 140 & 74.27 & 74.74 \\
9 & 140 & 77.99 & 85.52 \\
10 & 140 & 150.82 & 141.74 \\
\hline
\end{tabular}

Note 1: uncertainty due to GC analysis is evaluated lower than $10 \%$ or $1 \mathrm{ppm}$ (the higher of the two).

The values obtained by chemical analysis of the samples generated with vaporisation temperature equal to $270{ }^{\circ} \mathrm{C}$ are lower than the expected values; whereas the values obtained by chemical analysis of the samples generated with vaporisation temperature equal to $140^{\circ} \mathrm{C}$ are consistent to the expected values, as shown in Figure 3 .

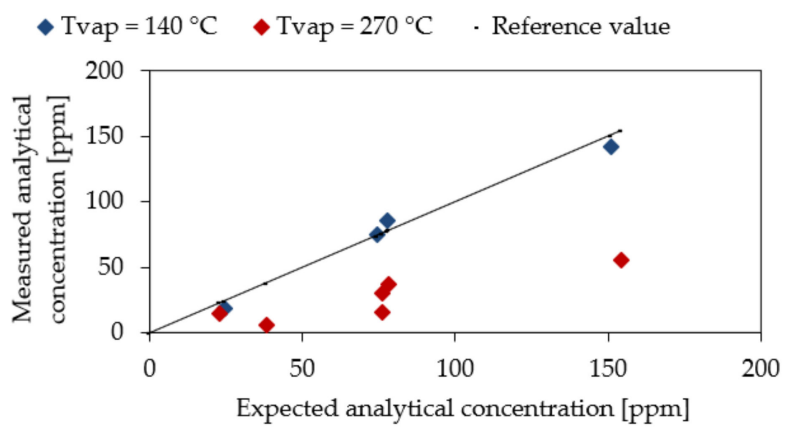

Figure 3. Scatter diagram of between concentration of butanol measured by the chromatograph $\left(\mathrm{C}_{\mathrm{yOH}}\right.$ expressed in ppm of butanol) and the concentration expected due the generation process $\left(\mathrm{C}_{\mathrm{xOH}}\right.$ expressed in ppm of butanol); data obtained at $140{ }^{\circ} \mathrm{C}$ are very near the ideal curve $\mathrm{C}_{\mathrm{yOH}}=\mathrm{C}_{\mathrm{xOH}}$.

In fact, the chromatograms obtained in the two cases are very different from each other. Figure 4 presents the characteristic chromatogram of the samples generated with a vaporisation temperature equal to $140^{\circ} \mathrm{C}$. There is only one peak with the characteristic retention time of n-butanol, equal to $1.89 \mathrm{~min}$.

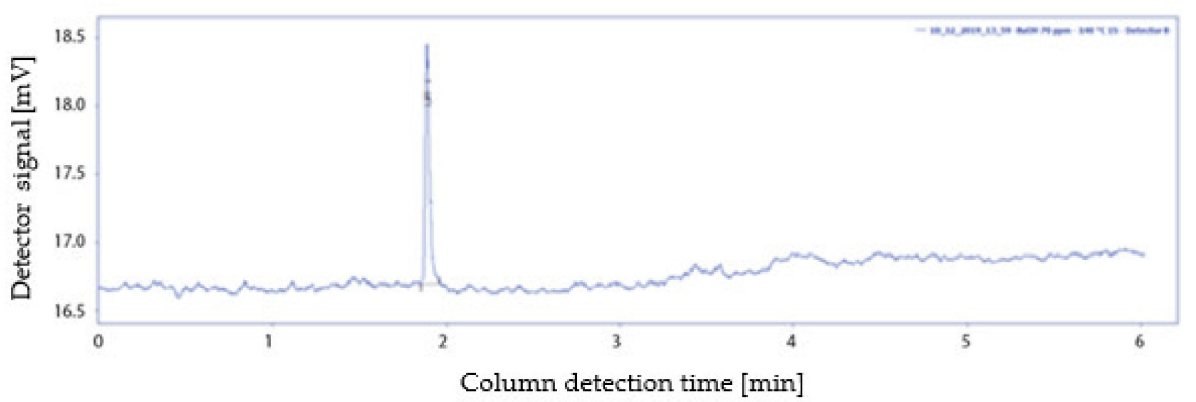

Figure 4. Chromatogram obtained from one of the samples generated with a vaporisation temperature equal to $140^{\circ} \mathrm{C}$; visible pack at $1.89 \mathrm{~min}$ is related to butanol and is verified using a traceable gas standard.

Figure 5 presents the characteristic chromatogram of the samples generated with a vaporisation temperature equal to $270{ }^{\circ} \mathrm{C}$, in which it is possible to see: 
- A peak with the characteristic retention time of n-butanol, $1.89 \mathrm{~min}$, but with a lower peak area than expected;

- A peak with a lower retention time then that characteristic of $n$-butanol, equal to $1.46 \mathrm{~min}$.

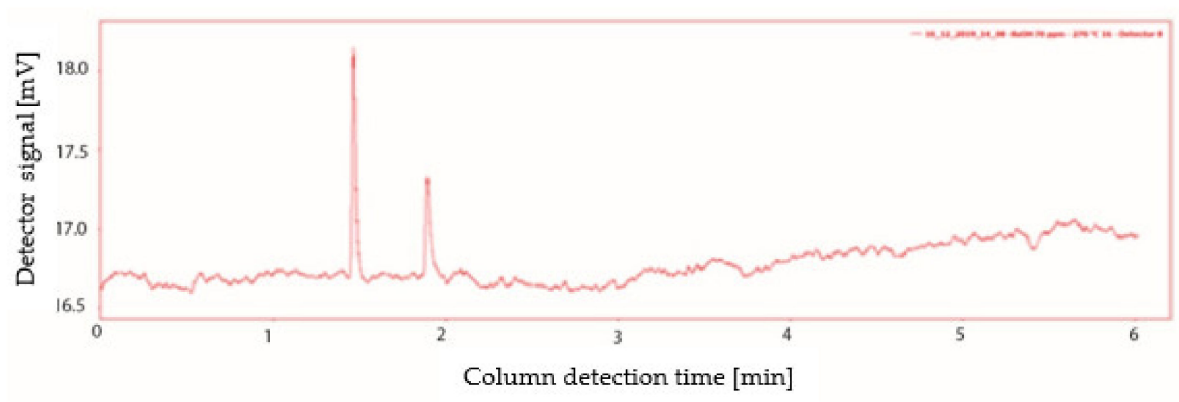

Figure 5. Chromatogram of one of the samples generated with a vaporisation temperature equal to $270{ }^{\circ} \mathrm{C}$; set-up conditions are identical, as in the test showed in Figure 4 . In this case, two peaks are present, one at $1.89 \mathrm{~min}$ and the second at $1.46 \mathrm{~min}$.

Furthermore, the values obtained from an olfactometry analysis, carried out with an TO8 olfactometer, of the samples generated with a vaporisation temperature equal to $270{ }^{\circ} \mathrm{C}$, were higher than the expected values, as shown in Figure 6.

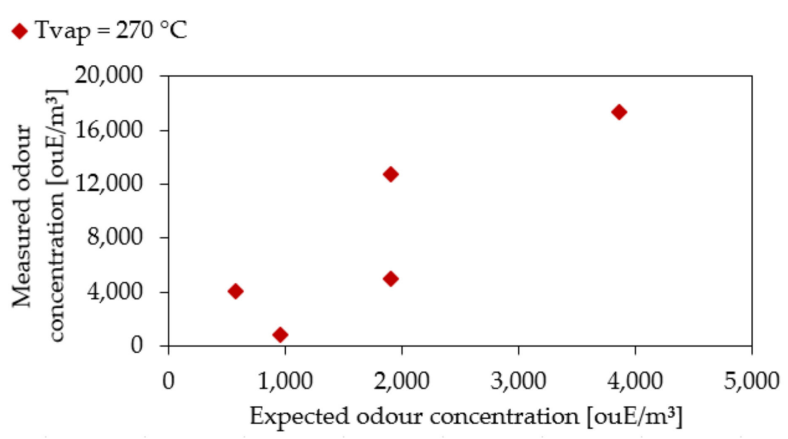

Figure 6. Scatter diagram of olfactometry analysis results for samples with Tvap $=270{ }^{\circ} \mathrm{C}$ with respect to the expected values, defined by the analytical values generated.

It is assumed that this phenomenon was due to decomposition of n-butanol caused by high temperatures. The components generated by thermal degradation were not determined, and will be studied in future works.

Based on available data, one of these compounds generated by the decomposition of $\mathrm{n}$-butanol is determined by the FID analysis and is lighter than n-butanol itself.

In subsequent tests, the vaporisation temperature was reduced to $140{ }^{\circ} \mathrm{C}$. This temperature allows obtaining complete vaporisation of the flow rate required for subsequent tests, up to $5 \mathrm{~mL} / \mathrm{min}$ of liquid solution, and it seems to prevent the decomposition of $\mathrm{n}$-butanol.

The results are not definitive, but they are valid in a case that considered a sample of gases and vapour, containing only nitrogen, $\mathrm{N}_{2}$, $\mathrm{n}$-butanol, and water vapour.

\section{Results}

\subsection{Execution of the Tests}

In October 2019, an experimental campaign was conducted in order to verify the possibility of evaluating sampling uncertainties in odour measurements using a synthetic bench loop.

A sample of nitrogen and water vapour, with a known n-butanol concentration, was generated inside the bench loop. The n-butanol concentration was constantly monitored using a portable FID (Mercury 901, N.I.R.A., Biassono (MB), Italy) 
The sampling was carried out from one of the five sampling ports, shown in Figure 7.

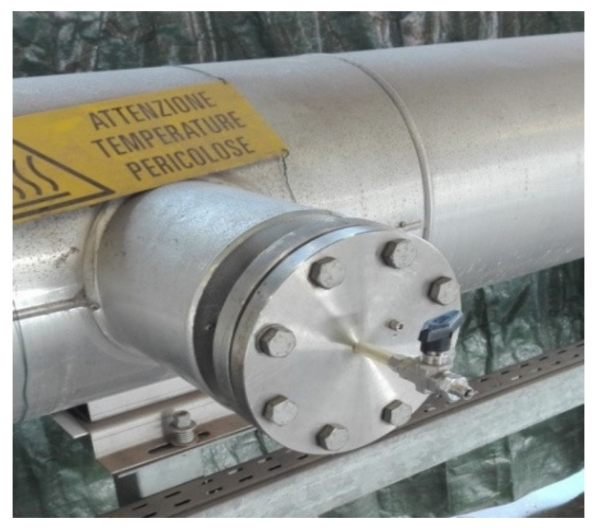

Figure 7. Sampling port.

The samples were analysed within $30 \mathrm{~h}$ after sampling, conforming to standard EN 13725. Olfactometry and a chemical analysis were carried out on the samples taken in order to obtain, respectively:

- $\mathrm{n}$-Butanol concentration value, expressed in $\mathrm{ppm}$;

- Odour concentration value, expressed in $\mathrm{ouE} / \mathrm{m}^{3}$.

The measured values were compared with the reference values, which were calculated, as described above.

\subsection{Measurement Uncertainties}

Quality criteria for the overall performance of the sensory measurement method are indicated in European standard EN 13725. Compliance with the quality criteria has to be assessed by performance testing to demonstrate and ensure compliance on a regular basis. According to this standard, the European Reference Odour Mass, EROM, for n-butanol, is used as the conventional quantity value when assessing trueness and precision.

If those criteria are respected in the analysis of reference materials, the standard provides for the use of n-butanol; this quality level can be considered transferable to other odorous substances [12].

The accuracy reflects both the trueness, expressed as bias, and the precision and random error. The test variable for accuracy is $A_{o d}$.

The criterion for accuracy of the odour concentration is:

$$
A_{o d}=d_{w}+A_{w} * r \leq 0.217
$$

where $A_{W}$ is a statistical factor; $d_{w}$ is the trueness, expressed as the estimate of withinlaboratory bias; $r$ is the repeatability limit.

In addition to the overall accuracy criterion, the precision, expressed as repeatability limit, complies with:

$$
r \leq 0.477
$$

This requirement implies that the factor that expresses the difference between two consecutive single measurements, performed on the same testing material in one laboratory under repeatability conditions, will not be larger than a factor 3 in $95 \%$ of cases.

The standard EN 13725 indicates that the geometric mean of the individual threshold

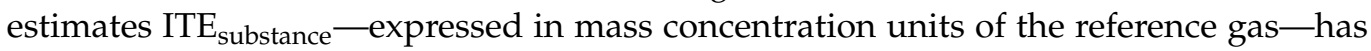
to fall between 0.5 and 2 times the conventional quantity value for that reference material, for n-butanol, from $62 \mu \mathrm{g} / \mathrm{m}^{3}$ to $246 \mu \mathrm{g} / \mathrm{m}^{3}=0.020 \mu \mathrm{mol} / \mathrm{mol}$ to $0.080 \mu \mathrm{mol} / \mathrm{mol}$. This means that $95 \%$ of the measurements can be found between 50 and $200 \%$ of the expected concentration. 
These performance criteria cannot be used to express the odour measurement uncertainty for the laboratory because it does not consider the sampling phase.

When a laboratory estimates a general uncertainty for all ordinary measurements carried out by the laboratory, then the measurement uncertainty shall be calculated during an ordinary measurement. This means that the usual analysis condition must be respected, and non-optimised procedures, which tend to reduce uncertainty, cannot be used.

The expanded uncertainty $U$ is expressed as a two-sided confidence interval [13]:

$$
\begin{aligned}
& \log _{10}\left(C_{o d}\right) \geq \log _{10}\left(C_{o d}\right)-\delta_{w, C R M}-U\left(\log _{10}\left(C_{o d}\right)\right) \\
& \log _{10}\left(C_{o d}\right) \leq \log _{10}\left(C_{o d}\right)-\delta_{w, C R M}+U\left(\log _{10}\left(C_{o d}\right)\right)
\end{aligned}
$$

In antilog terms, the coverage interval, confidence interval, is:

$$
C_{o d} * 10^{-\delta_{w-C R M}-U} \leq C_{o d} \leq C_{o d} * 10^{-\delta_{w-C R M}+U}
$$

The expanded uncertainty of measurement of the logarithm of the odour concentration of environmental samples is:

$$
U\left(\log _{10}\left(C_{o d}\right)\right)=k * u_{c}
$$

where $k$ is the coverage factor; an appropriate coverage factor is $k=2$ to express a $95 \%$ coverage probability; $u_{c}$ is the combined standard uncertainty of measurement of the logarithm of the odour concentration of environmental samples.

In an investigation of a single sampling target, if the sources of variation are independent, the measurement variance $\sigma_{\text {meas }}^{2}$ is given by:

$$
\sigma_{\text {meas }}^{2}=\sigma_{\text {sampling }}^{2}+\sigma_{\text {analytical }}^{2}
$$

where $\sigma_{\text {sampling }}^{2}$ is the between-sample variance on one target, and $\sigma_{\text {analytical }}^{2}$ is the betweenanalysis variance on one sample.

If statistical estimates of variance, $s^{2}$, are used to approximate these parameters, the standard uncertainty, $u_{c}$, can be estimated [14]:

$$
u_{c}=s_{\text {meas }}=\sqrt{s_{\text {sampling }}^{2}+s_{\text {analyical }}^{2}}
$$

It is not possible to distinguish these two contributions, but both must be considered in order to have an analysis that is, as much as possible, representative of the real measurement uncertainty.

In dynamic olfactometry, to verify laboratory compliance with performance quality criteria, PTs are carried out using dry samples containing air and buthanol. In these cases, only the contribution to uncertainty related to the analysis of the sample is investigated.

The tests, shown in this publication, were carried out to verify the possibility of using the bench loop to generate the odour sample with a known odour concentration; with this procedure, it would also be possible to investigate the contribution to uncertainty related to the sampling phase.

\subsection{Experimental Results}

In 2019, tests were conducted to verify the capability of the procedure to generate an odour sample with a known odour concentration, in order to evaluate measurement uncertainty as accurate as possible.

During the same testing day, gas samples containing gradually increasing odour concentrations were generated and sampled. The samples were analysed both from a chemical and olfactometry point of view; the results are shown in Table 2. 
Table 2. Chemical and olfactometry results.

\begin{tabular}{cccccc}
\hline Sample & $\begin{array}{c}\text { CbuOH } \\
\text { Expected } \\
(\mathbf{p p m})\end{array}$ & $\begin{array}{c}\text { CbuOH } \\
\text { Measured } \\
(\mathbf{p p m})\end{array}$ & $\begin{array}{c}\text { Cod } \\
\text { Expected } \\
\left(\mathbf{o u E} / \mathbf{m}^{\mathbf{3}}\right)\end{array}$ & $\begin{array}{c}\text { Cod } \\
\text { Measured } \\
\left(\mathbf{o u E} / \mathbf{m}^{\mathbf{3}}\right)\end{array}$ & $\begin{array}{c}\text { Confidence } \\
\text { Interval }\end{array}$ \\
\hline 1 & 23.23 & 18.66 & 580 & 542 & $262-1084$ \\
2 & 40.67 & 36.81 & 1016 & 1085 & $543-2170$ \\
3 & 56.57 & 56.94 & 1414 & 1218 & $609-2436$ \\
4 & 74.36 & 69.52 & 1859 & 1934 & $495-1934$ \\
5 & 106.92 & 102.24 & 2673 & 2436 & $609-2436$ \\
\hline
\end{tabular}

In this test, the vaporisation temperature was maintained at $140{ }^{\circ} \mathrm{C}$, in accordance with the results of previous tests. Moreover, in the bench loop, a sample of nitrogen, n-butanol, and water vapour was injected; so the results shown refer to this particular scenario in which interfering gases, e.g., $\mathrm{CO}_{2}$, are not injected.

Figure 8 presents the results of the chemical analysis of the samples taken; the values measured are consistent with the expected values.

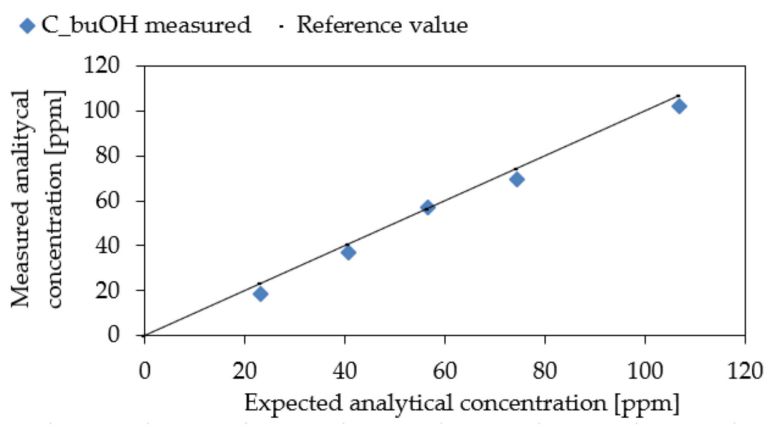

Figure 8. Scatter diagram of between concentration of butanol measured by the chromatograph $\left(\mathrm{C}_{\mathrm{yOH}}\right.$ expressed in ppm of butanol) and the concentration expected due the generation process at $140{ }^{\circ} \mathrm{C}\left(\mathrm{C}_{\mathrm{xOH}}\right.$ expressed in ppm of butanol) obtained during the second field trial.

Figure 9 presents the results of the olfactometry analysis. For each measured value, the confidence interval, calculated in compliance with the standard EN 13725, is indicated.

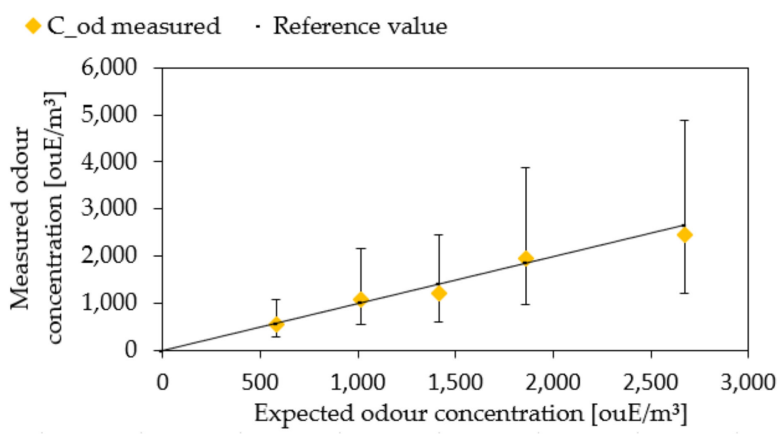

Figure 9. Scatter diagram of between odour concentrations determined using the EN 13752 method and the expected values, due to the generation process at $140{ }^{\circ} \mathrm{C}\left(\mathrm{C}_{\mathrm{xOH}}\right.$ expressed in ppm of butanol), obtained during the second field trial.

Considering the confidence interval, the measured values are consistent with the expected values.

Furthermore, the measured data were subjected to basic statistical processing. The z-score method was used to assess the results, as indicated in the standard EN 13528 [15], using Equation (11).

$$
Z^{*}=\frac{X_{\text {lab_norm }}-1}{\sigma}
$$




$$
X_{\text {lab_norm }}=\frac{X_{\text {lab }}}{X_{\text {ref }}}
$$

The measured values were normalised, as shown in Equation (12), with respect to the reference value. The standard deviation of the proficiency assessment used is equal to:

$$
\sigma=0.10(10 \%)
$$

The conventional interpretation of z-scores is as follows: a result that gives $|z| \leq 2$ is considered acceptable; a result that gives $2<|z| \leq 3$ is considered a warning signal; a result that gives $|z| \geq 3$ is considered unacceptable.

The results are shown in Figure 10; all measured values can be considered acceptable.

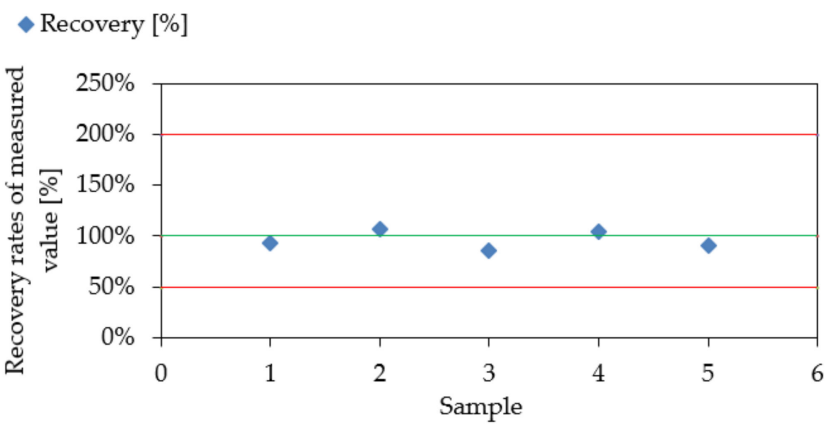

Figure 10. Recovery rates of measured values obtained during the second field trial, considering the relative difference between the measured concentrations in relation with the expected ones, obtained during the second field trial.

Moreover, in order to evaluate the variability of the results, the recovery rate was calculated. Figure 11 shows the recovery rates of the measured values. The variability is in a range between $86 \%$ and $107 \%$; these results are located between $50 \%$ and $200 \%$ of the expected concentration as indicated in the standard EN 13725.

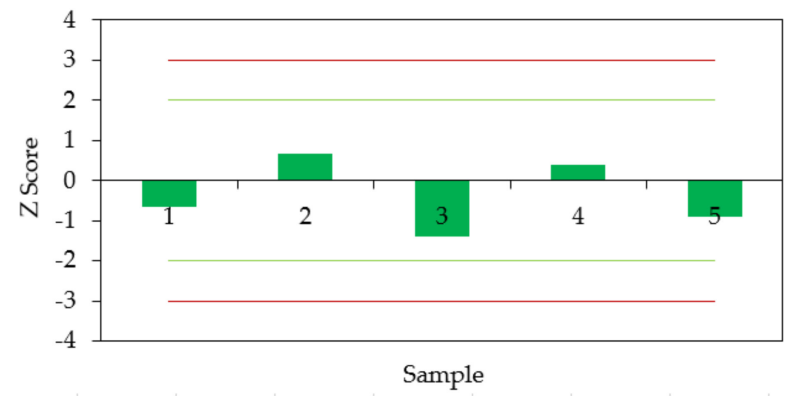

Figure 11. Z Score values obtained for the different concentrations during the second field trial, using the formulation given by EN 13528; in this case, the value of standard deviation selected is $10 \%$ of the expected value.

\section{Conclusions}

The tests were carried out for the essential purpose of designing and upgrading experimental protocols to evaluate sampling uncertainties in odour measurements using synthetic bench loops.

To generate the high levels of butanol needed (up to $500 \mathrm{ppm}$ was necessary prior to dilution into the bench), a vaporisation system was realised and tested, as gas cylinders are not available at such concentrations.

A first test was carried out in order to verify the possibility of generating an odour atmosphere with the target composition. 
Results obtained are consistent with the expected values. Moreover, z-scores and recovery rates for each value were calculated. Data obtained showed variability of the values in the range of $86 \%$ to $107 \%$, verifying that all results could be considered acceptable, as indicated by the standard EN 13725.

Such an experimental protocol seems to offer the possibility of evaluating sampling uncertainties in odour measurements. Therefore, it allows combining the traditional scheme of inter-laboratory comparison, in which the sampling process is not investigated, and the real measurement, in which the reference value is unknown, using the bench loop. In fact, in the tests carried out with this procedure, it was possible to generate an odorous sample with a known odour concentration.

This procedure would also allow evaluating the transport and storage phases, verifying the sample stability in this period. Moreover, new sampling methods could be analysed using the bench loop.

One interesting future scenario would be injecting interfering gases, e.g., $\mathrm{CO}_{2}$, in the bench loop in order to evaluate the influence that the presence of those gases could have on the odour concentration measurement.

Another interesting aspect would be evaluating the influence of a change in temperature and humidity on the measured odour concentration in samples with a known n-butanol concentration. In fact, the bench loop allows regulating and maintaining a constant temperature and humidity inside the conduit. It would be significant to investigate the impact these factors have on sampling uncertainty.

Author Contributions: Conceptualization, D.C.; methodology, D.C.; validation, D.C.; data curation, D.C., A.M.C., M.A.; writing-original draft preparation, D.C.; writing-review and editing, D.C., A.M.C. All authors have read and agreed to the published version of the manuscript.

Funding: This research received no external founding.

Institutional Review Board Statement: Not applicable.

Informed Consent Statement: Not applicable.

Data Availability Statement: The datasets used and/or analysed during the current study are available from the corresponding author on reasonable request.

Conflicts of Interest: The authors declare no conflict of interest. The funders had no role in the design of the study; in the collection, analyses, or interpretation of data; in the writing of the manuscript, or in the decision to publish the results.

\section{References}

1. CEN. EN13725, Air Quality-Determination of Odour Concentration by Dynamic Olfactometry and Odour Emission Rate from Stationary by Sources; CEN: Brussels, Belgium, 2004.

2. Freeman, T.; Needham, C.; Schulz, C. CH2M BECA Analysis of Options for Odour Evaluation for Industrial or Trade Processes; Auckland Regional Council CH2M BECA Ltd.: Auckland, New Zealand, 2000.

3. Gwynne, C.; Philips, L.; Turner, N.; Goldstone, M. Temporal and Spatial Variability of Odours at Wastewater Plants in Western Australia; Water Corporation: Melbourne, Australia, 2001.

4. Van Harreveld, A.P.; Heeres, P. The validation of the draft European CEN standard for dynamic olfactometry by an interlaboratory comparison on n-butanol. Gefahrst. Reinhalt. Luft 1997, 57, 393-398.

5. Ramsdale, S.L.; Baillie, C.P. Interlaboratory test program: Odour detection threshold for hydrogen sulphide. J. Clean Air Soc. Aust. N. Z. 1996, 30, 36-37.

6. Defoer, N.; Van Langenhove, H. Variability and repeatability of olfactometric results of n-butanol, pig odour and synthetic gas mixture. Water Sci. Technol. 2004. [CrossRef]

7. Clanton, C.J.; Schmidt, D.R.; Nicolai, R.E.; Goodrich, P.R.; Jacobson, L.D.; Janni, K.A.; Weisberg, S.; Buckel, J.A. Dynamic olfactometry variability in determining odor dilutions-to-threshold. Trans. ASAE 1999, 42, 1103-1112. [CrossRef]

8. Stöckel, S.; Cordes, J.; Stoffels, B.; Wildanger, D. Scents in the stack: Olfactometric proficiency testing with an emission simulation apparatus. Environ. Sci. Pollut. Res. 2018, 25, 24787-24797. [CrossRef] [PubMed]

9. Cipriano, D.; Fialdini, L. Definition of reference values in synthetic emission monitoring bench loop. Accredit. Qual. Assur. 2018. [CrossRef] 
10. ISO. ISO Guide 35, Reference Materials_Guidance for Characterization and Assessment of Homogeneity and Stability; ISO: Geneva, Switzerland, 2017.

11. ISO. ISO/IEC 17043, Conformity Assessment-General Requirements for Proficiency Testing; ISO: Geneva, Switzerland, 2010.

12. Van Harreveld, A.P.; Heeres, P. Quality control and optimization of dynamic olfactometry using n-Butanol as a standard reference odorant. Staub Reinhalt. Luft 1995, 55, 45-50.

13. JCGM. GUM Guide to the Expression of Uncertainty in Measurement; JCGM: Geneva, Switzerland, 2008.

14. EURACHEM/CITAC. Measurement Uncertainty Arising from Sampling-A Guide to Method and Approaches, 2nd ed.; EURACHEM: Teddington, Middlesex, UK, 2019.

15. ISO. ISO 13528 (2015), Statistical Methods for Use in Proficiency Testing by Interlaboratory Comparison; ISO: Geneva, Switzerland, 2015. 